\title{
Phase II Study of Consolidation Amrubicin After Concurrent Chemoradiotherapy in Patients With Limited-stage Small-cell Lung Cancer
}

\author{
HIRONORI YOSHIDA ${ }^{1}$, HIROKI NAGAI ${ }^{2}$, YUICHI SAKAMORI ${ }^{2}$, HIROAKI OZASA $^{1}$, \\ TAKASHI NISHIMURA ${ }^{3}$, KEISUKE TOMII ${ }^{4}$, TOYOHIRO HIRAI ${ }^{1}$, YUKINORI MATSUO ${ }^{5}$, \\ YUSUKE IIZUKA $^{5}$, TAKASHI MIZOWAKI ${ }^{5}$, KENICHI YOSHIMURA ${ }^{6}$ and YOUNG HAK KIM ${ }^{1}$ \\ ${ }^{I}$ Department of Respiratory Medicine, Graduate School of Medicine, Kyoto University, Kyoto, Japan; \\ ${ }^{2}$ Department of Therapeutic Oncology, Graduate School of Medicine, Kyoto University, Kyoto, Japan; \\ ${ }^{3}$ Department of Respiratory Medicine, Kyoto Katsura Hospital, Kyoto, Japan; \\ ${ }^{4}$ Department of Respiratory Medicine, Kobe City Medical Center General Hospital, Kobe, Japan; \\ ${ }^{5}$ Department of Radiation Oncology and Image-applied Therapy, \\ Graduate School of Medicine, Kyoto University, Kyoto, Japan; \\ ${ }^{6}$ Center for Integrated Medical Research, Hiroshima University Hospital, \\ Hiroshima University, Hiroshima, Japan
}

\begin{abstract}
Background: Concurrent chemoradiotherapy (CCRT) is the gold standard for limited-stage small-cell lung cancer (LS-SCLC); however, most patients inevitably experience relapse. We hypothesized consolidation amrubicin following CCRT to be a potential treatment for $L S$-SCLC. Patients and Methods: All enrolled patients were treated using induction CCRT consisting of four cycles of etoposide and cisplatin plus concurrent thoracic radiotherapy. Eligible patients then received three cycles of amrubicin as consolidation therapy (consolidation population). The primary endpoint was the 2-year progression-free survival rate in the consolidation population. Results: Of the 36 intention-to-treat patients, 28 (78\%) received amrubicin and 24 (67\%) completed all planned treatments. The 2-year progression-free survival rate and overall response rate were $35.7 \%$ and $86 \%$, respectively. The median progression-free and overall survival were 14.3 and 60.9 months, respectively. There were no treatment-related deaths in the intention-totreat population. Conclusion: This study was terminated due
\end{abstract}

This article is freely accessible online.

Correspondence to: Young Hak Kim, MD, Ph.D., Department of Respiratory Medicine, Graduate School of Medicine, Kyoto University, 54 Shogoin-Kawaharamachi Sakyo-Ku, 606-8507 Kyoto, Japan. Tel: +81 757513830, Fax: +81 757514643, e-mail: ekim@kuhp.kyoto-u.ac.jp

Key Words: LS-SCLC, chemoradiotherapy, consolidation, amrubicin. to slow patient accrual; however, this treatment strategy was feasible and demonstrated promising efficacy.

Approximately $15 \%$ of all lung cancers are diagnosed as small-cell lung cancer (SCLC), and approximately one-third are classified as limited-stage (LS)-SCLC in the US (1). For decades, the standard treatment for LS-SCLC has been concurrent chemoradiotherapy (CCRT), consisting of four cycles of etoposide and cisplatin plus concurrent thoracic radiotherapy (TRT) (2-4). Although SCLC is highly sensitive to both chemotherapy and radiotherapy, most patients eventually experience relapse, resulting in only one out of four patients surviving for more than 5 years $(3,4)$.

Amrubicin, a fully synthetic 9-aminoanthracycline, is converted to an active metabolite, amrubicinol, by reduction of the 13-position ketone. Amrubicin has a structure similar to that of doxorubicin, which mainly acts as a DNA intercalator, whereas amrubicin and amrubicinol have cytotoxic effects as DNA topoisomerase II inhibitors instead of DNA intercalators (5). Although a phase III study failed to demonstrate the superiority of amrubicin in terms of overall survival (OS) compared with standard topotecan in patients with relapsed SCLC, the overall response rate (ORR) and progression-free survival (PFS) were significantly better in the amrubicin arm. Of note, the OS was significantly better in the amrubicin arm in the refractory relapsed subset (6). Since its approval in 2002, amrubicin has been widely used as a standard secondline treatment for SCLC in Japan.

LS-SCLC is potentially curable by chemoradiotherapy; however, once relapsed, it is markedly difficult to cure. 
Induction phase

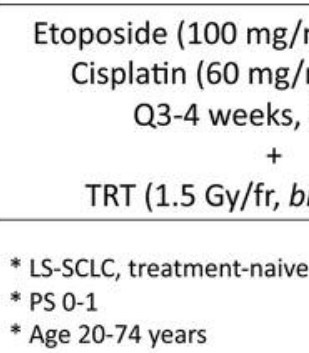

\section{Consolidation phase}

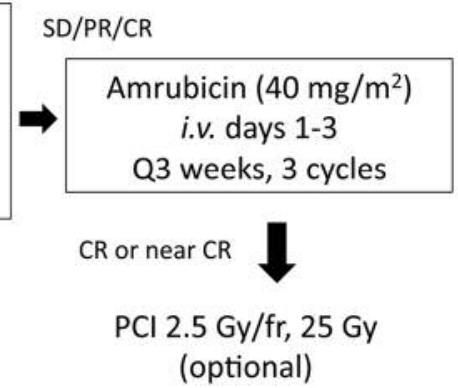

Figure 1. Study schema. bid: Twice daily; CR: complete response; i.v.: Intravenously; LS-SCLC: limited-stage small-cell lung cancer; PCI: prophylactic cranial irradiation; PR: partial response; PS: performance status; SD: stable disease; TRT: thoracic radiotherapy.

Therefore, potentiating initial treatment is essential for improving the cure rate in patients with LS-SCLC. Considering its efficacy, especially for refractory relapsed SCLC, we considered the integration of amrubicin into the initial treatment for LS-SCLC to be a promising strategy. Thus, we conducted a phase II study to evaluate the safety and efficacy of consolidation amrubicin following standard CCRT in patients with LS-SCLC.

\section{Patients and Methods}

Patient selection. Patients with histologically or cytologically confirmed LS-SCLC were eligible for the study. LS-SCLC was defined as disease confined to one hemithorax, including the ipsilateral hilar, bilateral mediastinal, and bilateral supraclavicular lymph node metastases. Pleural effusion of less than $1 \mathrm{~cm}$ by chest computed tomography (CT) was allowed, but patients with malignant pleural effusion were excluded. Each patient was required to meet the following criteria: No prior chemotherapy or radiotherapy, age 20-74 years, Eastern Cooperative Oncology Group performance status (ECOG PS) of 0 or 1, measurable lesions, adequate hematological function [white blood cell count (WBC) $\geq 3,000 / \mathrm{mm}^{3}$; platelets $\geq 100,000 / \mathrm{mm}^{3}$; hemoglobin $\left.\geq 9.0 \mathrm{~g} / \mathrm{dl}\right]$, and sufficient hepatic function [aspartate aminotransferase (AST) and alanine aminotransferase (ALT) $\leq 100 \mathrm{IU} / \mathrm{l}$; total bilirubin $\leq 1.5$ $\mathrm{mg} / \mathrm{dl}$ ] and renal function (creatinine $\leq 1.5 \mathrm{mg} / \mathrm{dl}$ ). Patients with pericardial effusion, active concomitant malignancy, prior second primary cancer, active infection, severe heart disease, history of myocardial infarction in the previous 3 months, unstable angina, uncontrollable diabetes mellitus or hypertension, interstitial pneumonia or active lung fibrosis on chest radiograph, or psychiatric disease were excluded. This study was approved by the Institutional Review Board of each participating institution. Written informed consent was received from all patients (Clinical trial registration: UMIN000002352).

Treatment schedule. The study schema is shown in Figure 1. Induction treatment, consisting of etoposide at $100 \mathrm{mg} / \mathrm{m}^{2}$ on days 1-3 and cisplatin at $60 \mathrm{mg} / \mathrm{m}^{2}$ on day 1 , was started within 7 days from registration. Etoposide was administered as a 1- to 2-h intravenous infusion, and cisplatin as a 1- to 2-h intravenous infusion with sufficient hydration. TRT was started on day 1 of the first cycle of etoposide-cisplatin and administered at a fraction dose of 1.5 Gy twice daily to a total dose of 45 Gy in 3 weeks. The second cycle of etoposide-cisplatin was given 4 weeks after the first cycle of etoposide-cisplatin, and an additional three cycles of etoposide-cisplatin was continued every 3 weeks unless the disease progressed or intolerable toxicities were observed. All the patients who were enrolled in the study were defined as the intention-to-treat (ITT) population.

After the induction treatment, patients were reassessed for the following criteria for the administration of consolidation amrubicin: completion of the defined induction treatment, no progressive disease [complete response (CR), partial response (PR), or stable disease (SD)] within 42 days from the start of the fourth cycle of etoposide-cisplatin, ECOG PS of $0-2, \mathrm{WBC} \geq 3,000 / \mathrm{mm}^{3}$, platelets $\geq 100,000 / \mathrm{mm}^{3}$, bilirubin $\leq 1.5 \mathrm{mg} / \mathrm{dl}$, AST and ALT $\leq 100 \mathrm{IU} / 1$, creatinine $\leq 2.0 \mathrm{mg} / \mathrm{dl}$, fever $<37.5^{\circ} \mathrm{C}$, no active infection, radiation dermatitis or esophagitis of grade 2 or less, and no pulmonary infiltration beyond the irradiated field. All eligible patients received three cycles of amrubicin at $40 \mathrm{mg} / \mathrm{m}^{2}$ on days $1-3$ every three weeks (consolidation population). Amrubicin was administered as a 5-min intravenous injection. Prophylactic cranial irradiation (PCI) was optional for patients who achieved $\mathrm{CR}$ or near $\mathrm{CR}$ by the above treatment.

Thoracic radiotherapy. TRT was delivered from megavoltage equipment (6-10 MV) at a fraction dose of $1.5 \mathrm{~Gy}$ twice daily, with at least a 6-h interval between the fractions, to a total dose of 45 Gy in 30 fractions in 3 weeks. All patients underwent threedimensional treatment-planning computed tomography within 7 days before the start of the treatment. The gross tumor volume (GTV) included the pretreatment primary GTV and metastatic lymph nodes of $1 \mathrm{~cm}$ or larger in the short axis diameter on computed tomographic images. The clinical target volume (CTV) was equal to the GTV and uninvolved mediastinal and ipsilateral hilar nodes. The other regions were not routinely included unless metastatic nodes were noted. The contralateral hilar lymph node was excluded from the CTV. The planning target volume (PTV) included the CTV plus sufficient margins (typically $0.5-1.0 \mathrm{~cm}$ laterally and $1.0-2.0 \mathrm{~cm}$ craniocaudally). The volume of the lung unaffected by cancer which would receive 20 Gy or more was kept to $35 \%$ or less. Heterogeneity corrections were applied to monitor unit calculations. 
Table I. Patient characteristics.

\begin{tabular}{llcc}
\hline & & $\begin{array}{c}\text { ITT population } \\
(\mathrm{N}=36)\end{array}$ & $\begin{array}{c}\text { Consolidation population } \\
(\mathrm{N}=28)\end{array}$ \\
\hline Age & Median (range) & $65(54-75)$ & $64(54-74)$ \\
Gender & Male & $25(69 \%)$ & $18(64 \%)$ \\
& Female & $11(31 \%)$ & $10(36 \%)$ \\
ECOG PS & 0 & $30(83 \%)$ & $22(79 \%)$ \\
& 1 & $6(17 \%)$ & $6(21 \%)$ \\
\hline
\end{tabular}

ITT: Intention-to-treat; ECOG: Eastern Cooperative Oncology Group; PS performance status.

Evaluation of toxicity and dose modification. Toxicity was evaluated based on the National Cancer Institute-Common Terminology Criteria, version 4.0 (7). Blood tests and chest $\mathrm{x}$-ray were required at least once a week during TRT, and at least once 2 weeks after the completion of TRT. If patients had $\mathrm{WBC}<1,000 / \mathrm{mm}^{3}$, neutrophils $<500 / \mathrm{mm}^{3}$, platelets $<25,000 / \mathrm{mm}^{3}$, or grade 3 non-hematological toxicities other than nausea, vomiting, fatigue, alopecia, and transient electrolyte disturbances, the doses of etoposide, cisplatin, and amrubicin were reduced by 20,10 , and $5 \mathrm{mg} / \mathrm{m}^{2}$, respectively, in subsequent cycles. If the creatinine level was greater than 1.5 $\mathrm{mg} / \mathrm{dl}$ during the etoposide-cisplatin treatment, the dose of cisplatin was reduced to $50 \mathrm{mg} / \mathrm{m}^{2}$. The next cycle of etoposide-cisplatin was started when a patient had a WBC $\geq 3,000 / \mathrm{mm}^{3}$, platelets $\geq 100,000 / \mathrm{mm}^{3}$, bilirubin $\leq 2.0 \mathrm{mg} / \mathrm{dl}$, AST and ALT $\leq 100 \mathrm{IU} / 1$, creatinine $\leq 1.5 \mathrm{mg} / \mathrm{dl}$, PS of $0-2$, and fever $<37.5^{\circ} \mathrm{C}$. Amrubicin was started when a patient had a WBC $\geq 3,000 / \mathrm{mm}^{3}$, platelets $\geq 100,000 / \mathrm{mm}^{3}$, bilirubin $\leq 2.0 \mathrm{mg} / \mathrm{dl}$, AST and ALT $\leq 100 \mathrm{IU} / 1$, creatinine $\leq 2.0 \mathrm{mg} / \mathrm{dl}$, PS of $0-2$, and fever $<37.5^{\circ} \mathrm{C}$. If PS of 3 or 4 , grade 2 pneumonitis or pulmonary infiltrates, or a fever of $38.0^{\circ} \mathrm{C}$ or higher developed, radiotherapy was withheld until recovery. If toxicities persisted and patients did not meet the above criteria for up to 14 days from the completion of the previous cycle of chemotherapy or from the termination of TRT, the study treatment was terminated. Use of granulocyte colony stimulating factor (GCSF) agents was allowed at the discretion of the treating physician, but prophylactic use was permitted only during the consolidation phase.

Evaluation of tumor response. Tumor response was assessed after the completion of TRT, during 8 to 28 days from the start of the fourth cycle of etoposide-cisplatin, and after the last cycle of amrubicin. Post-treatment evaluation was performed every 2 months until death or progressive disease. The ORR was evaluated according to the Response Evaluation Criteria in Solid Tumors (RECIST) version 1.1 (8).

Statistical analyses. The primary endpoint of the study was the 2year PFS rate in the consolidation population. The secondary endpoints were the ORR, PFS, OS, and toxicities in the ITT and consolidation populations. The targeted sample size was 33 for the consolidation population, with a one-sided alpha of 0.1 , a beta of 0.2 , and expected and threshold 2-year PFS rates of $40 \%$ and $25 \%$, respectively. Assuming the CCRT consisting of TRT and four cycles of etoposide-cisplatin to be completed by $85 \%$ of the patients, and
Table II. Treatment delivery.

\begin{tabular}{lcc}
\hline Treatment cycle & Cycle & $\mathrm{n}(\%)$ \\
\hline Etoposide/cisplatin & 1 & $36(100)$ \\
& 2 & $34(94)$ \\
& 3 & $33(92)$ \\
Amrubicin & 4 & $31(86)$ \\
& 1 & $28(78)$ \\
& 2 & $26(72)$ \\
& 3 & $24(67)$ \\
\hline
\end{tabular}

ITT: Intention-to-treat; ECOG: Eastern Cooperative Oncology Group; PS: performance status.

a disease control rate of $95 \%$, a total of 41 patients were required for the ITT population. If fewer than eight patients completed the three cycles of consolidation amrubicin among the first 17 patients, the study was to be terminated due to unfeasibility. The PFS and OS were estimated using the Kaplan-Meier method. The PFS was measured from the date of the first registration to disease progression, death from any cause, or the last follow-up. OS was measured from the date of the first registration to the date of death from any cause or the last follow-up. Patients who were lost to follow-up without events were censored at the last known date of follow-up. All patients who received at least one cycle of chemotherapy were considered assessable for response evaluation, and toxicity. All analyses were performed using JMP 14 software (SAS Institute, Cary, NC, USA).

\section{Results}

Patient characteristics. Between January 2010 and September 2016, 36 patients were enrolled in this study. Patient characteristics in the ITT population are listed in Table I. The median age was 65 years (range $=54$ to 75 years), $25(69 \%)$ patients were male, and 30 (83\%) patients had an ECOG PS of 0 .

Treatment delivery. All 36 patients completed the TRT of 45 Gy and $31(86 \%)$ completed the four cycles of etoposidecisplatin (Table II). The reasons for discontinuation of etoposide-cisplatin treatment were persisting toxicity in four (two of neutropenia, and one each of esophagitis, and creatinine increase) and cancer-unrelated death in one. Among the 31 patients who completed the induction phase, three did not enter the consolidation phase (one with progressive disease, one due to toxicity, and one patient refusal). Patient characteristics for the consolidation population are also listed in Table I. Of the ITT population, $28(78 \%)$ entered the consolidation phase and $24(67 \%)$ completed the planned three cycles of amrubicin (Table II). The reasons for discontinuation of amrubicin were patient refusal for one and worsening of radiation pneumonitis for three. Dose adjustment for etoposide-cisplatin and amrubicin 
Table III. Antitumor response.

\begin{tabular}{clcc}
\hline & \multicolumn{2}{c}{ Phase } \\
\cline { 3 - 4 } & & $\begin{array}{c}\text { Induction } \\
(\mathrm{n}=36)\end{array}$ & $\begin{array}{c}\text { Consolidation } \\
(\mathrm{n}=28)\end{array}$ \\
\hline Overall & No. of patients with response & 30 & 2 \\
response & Percentage of patients (95\% CI) & $83(68-92)$ & $7(2-23)$ \\
Objective & Complete response & $7(19)$ & $0(0)$ \\
response & Partial response & $23(64)$ & $2(7)$ \\
& Stable disease & $2(6)$ & $23(82)$ \\
& Progressive disease & $1(3)$ & $3(11)$ \\
& Not evaluable & $3(8)$ & $0(0)$ \\
\hline
\end{tabular}

CI: Confidence interval.

was required in $11(31 \%)$ and one patient (4\%), respectively. After the completion of all planned treatments, 18 out of 24 patients (75\%) received PCI.

Response and survival. Antitumor responses are shown in Table III. In the induction phase, seven (19\%) patients achieved CR and 23 (64\%) had PR with an ORR of $83 \%$ [95\% confidence interval $(\mathrm{CI})=68-92 \%]$. In the consolidation phase, 2 (7\%) had PR with an ORR of 7\% (95\% CI=2-23\%). Consequently, the ORR was $86 \%$ (95\% CI $=69-94 \%)$ in the consolidation population. The median PFS was 13.4 (95\% $\mathrm{CI}=7.5-19.0)$ months and 14.3 (95\% CI=10.8-46.6) months in the ITT and consolidation populations, respectively. The 2-year PFS rate was 30.6\% (95\% CI=18.0-46.9\%) and $35.7 \%(95 \% \mathrm{CI}=20.7-54.2 \%)$ in the ITT and consolidation populations, respectively (Figure 2A). After a median follow-up of 29.8 months (range=6.6-102.4 months), the median OS was 60.9 months $(95 \% \mathrm{CI}=29.8$ months-not reached) and 60.9 months (95\% CI=29.8 months-not reached) in the ITT and consolidation populations, respectively (Figure 2B).

Toxicity. Both hematological and non-hematologic toxicities are summarized in Table IV. During the induction phase, grade 3 or 4 neutropenia developed in $36(100 \%)$ patients, thrombocytopenia in five (14\%), and febrile neutropenia in seven (19\%). G-CSF was required for $32(89 \%)$ patients, but none required red blood cell or platelet transfusion. Grade 3 creatinine increase, anorexia, stomatitis, and esophagitis were observed in one (3\%) patient each.

During the consolidation phase, grade 3 or 4 neutropenia developed in $11(39 \%)$ patients, anemia in seven $(25 \%)$, thrombocytopenia in four (14\%), and febrile neutropenia in two $(7 \%)$. G-CSF was administered to 18 (64\%) patients, of whom six $(33 \%)$ received it as primary prophylaxis. Two (7\%) patients required red blood cell transfusion, but none required platelet transfusion. Five (18\%) patients developed grade 3 pneumonitis; all cases were considered radiationassociated pneumonitis and steroid-sensitive. There were no treatment-related deaths in the ITT population.

\section{Discussion}

In this study, we evaluated the safety and efficacy of consolidation amrubicin following standard CCRT. This study was terminated due to slow patient accrual. Therefore, no statistical conclusions can be made. However, this treatment strategy was feasible and demonstrated promising efficacy.

For decades, the standard treatment for LS-SCLC has been CCRT consisting of four cycles of etoposide-cisplatin plus concurrent TRT, associated with a 5-year survival rate of approximately $25 \%$. New treatment strategies are eagerly anticipated to improve outcomes in this setting. One such attempt is to modify the TRT dose and schedule. The CONVERT study team conducted a randomized phase III study comparing two different radiation schedules: $45 \mathrm{~Gy}$ in 30 twice-daily fractions of 1.5 Gy versus 66 Gy in 33 oncedaily fractions of 2 Gy in combination with 4-6 cycles of etoposide-cisplatin; however, there was no significant survival difference between the two arms (9).

Another such approach is to modify the chemotherapy regimen. The Japan Clinical Oncology Group (JCOG) demonstrated significant OS benefits of irinotecan plus cisplatin over etoposide-cisplatin for extensive-stage SCLC (10). Based on the results, JCOG conducted a randomized phase III study comparing irinotecan plus cisplatin with etoposide-cisplatin following concurrent TRT concomitant with one cycle of etoposide-cisplatin in patients with LS-SCLC; however, irinotecan plus cisplatin failed to exhibit any survival advantages (11). Recently, a Japanese group conducted a feasibility study of amrubicin plus cisplatin following concurrent TRT concomitant with one cycle of etoposidecisplatin in patients with LS-SCLC, and reported 5-year PFS and OS rates of $41.9 \%$ and $57.8 \%$, respectively. Although hematological toxicities were severe, and all patients developed grade 3 or 4 neutropenia and required G-CSF support, these data are encouraging (12). Combined with our results, the data show the strategy of consolidation amrubicin after CCRT in LS-SCLC is promising and warrants further investigation.

In recent years, immune checkpoint inhibitors have been extensively investigated for many malignancies, including SCLC, and atezolizumab, an antibody against programmed death-ligand 1, significantly improved the survival from extensive-stage SCLC in combination with chemotherapy (13). Future studies for LS-SCLC should focus on immune checkpoint inhibitors, and there are several on-going studies using them to target LS-SCLC. However, as chemotherapy is the mainstay in the treatment of SCLC, continuous effort to improve its effectiveness is essential. 

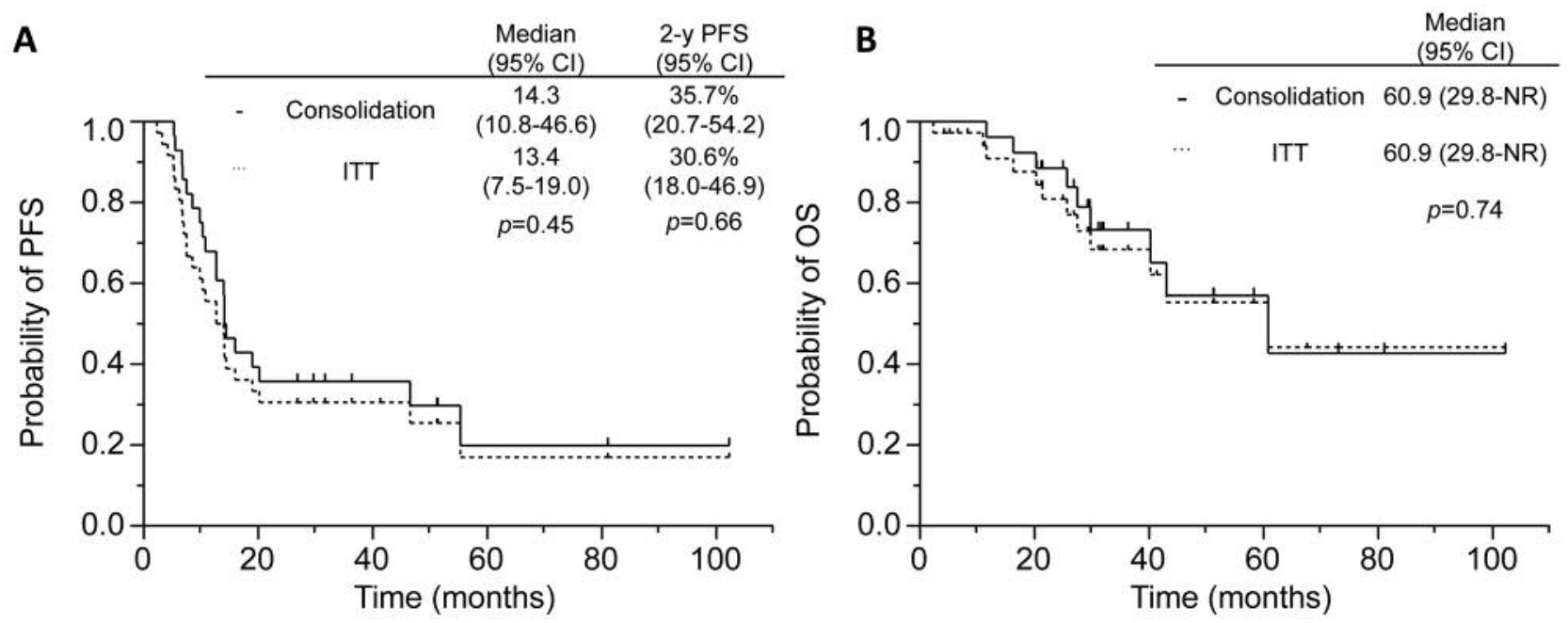

Figure 2. Kaplan-Meier curves for progression-free survival (PFS) (A) and overall survival (OS) (B). CI: Confidence interval; ITT: intention-totreat; NR: not reached.

Table IV. Hematological and non-hematological toxicities.

\begin{tabular}{|c|c|c|c|c|c|c|c|c|c|c|c|c|}
\hline \multirow[b]{2}{*}{ Grade } & \multicolumn{6}{|c|}{ Induction phase $(\mathrm{n}=36)$} & \multicolumn{6}{|c|}{ Consolidation phase $(\mathrm{n}=28)$} \\
\hline & 0 & 1 & 2 & 3 & 4 & $\geq 3, \mathrm{n}(\%)$ & 0 & 1 & 2 & 3 & 4 & $\geq 3, \mathrm{n}(\%)$ \\
\hline Neutropenia & 0 & 0 & 0 & 7 & 29 & $36(100)$ & 10 & 4 & 3 & 6 & 5 & $11(39)$ \\
\hline Anemia & 5 & 5 & 26 & 0 & 0 & $0(0)$ & 5 & 5 & 11 & 7 & 0 & $7(25)$ \\
\hline Thrombocytopenia & 14 & 12 & 5 & 4 & 1 & $5(14)$ & 17 & 4 & 3 & 4 & 0 & $4(14)$ \\
\hline Febrile neutropenia & 29 & 0 & 0 & 6 & 1 & $7(19)$ & 26 & 0 & 0 & 2 & 0 & $2(7)$ \\
\hline Bilirubin & 34 & 0 & 2 & 0 & 0 & $0(0)$ & 27 & 1 & 0 & 0 & 0 & $0(0)$ \\
\hline AST increase & 27 & 9 & 0 & 0 & 0 & $0(0)$ & 20 & 8 & 0 & 0 & 0 & $0(0)$ \\
\hline ALT increase & 25 & 11 & 0 & 0 & 0 & $0(0)$ & 24 & 3 & 1 & 0 & 0 & $0(0)$ \\
\hline Creatinine increase & 23 & 7 & 5 & 1 & 0 & $1(3)$ & 24 & 4 & 0 & 0 & 0 & $0(0)$ \\
\hline Nausea & 15 & 19 & 2 & 0 & 0 & $0(0)$ & 19 & 8 & 1 & 0 & 0 & $0(0)$ \\
\hline Vomiting & 33 & 3 & 0 & 0 & 0 & $0(0)$ & 28 & 0 & 0 & 0 & 0 & $0(0)$ \\
\hline Fatigue & 8 & 24 & 4 & 0 & 0 & $0(0)$ & 10 & 15 & 3 & 0 & 0 & $0(0)$ \\
\hline Anorexia & 11 & 17 & 7 & 1 & 0 & $1(3)$ & 15 & 12 & 1 & 0 & 0 & $0(0)$ \\
\hline Diarrhea & 33 & 2 & 1 & 0 & 0 & $0(0)$ & 27 & 1 & 0 & 0 & 0 & $0(0)$ \\
\hline Constipation & 14 & 22 & 0 & 0 & 0 & $0(0)$ & 22 & 6 & 0 & 0 & 0 & $0(0)$ \\
\hline Stomatitis & 28 & 7 & 0 & 1 & 0 & $1(3)$ & 22 & 6 & 0 & 0 & 0 & $0(0)$ \\
\hline Alopecia & 13 & 18 & 5 & 0 & 0 & $0(0)$ & 14 & 12 & 2 & 0 & 0 & $0(0)$ \\
\hline Pneumonitis & 32 & 3 & 1 & 0 & 0 & $0(0)$ & 6 & 8 & 9 & 5 & 0 & $5(18)$ \\
\hline Rash & 32 & 4 & 0 & 0 & 0 & $0(0)$ & 25 & 3 & 0 & 0 & 0 & $0(0)$ \\
\hline Esophagitis & 13 & 19 & 3 & 1 & 0 & $1(3)$ & 28 & 0 & 0 & 0 & 0 & $0(0)$ \\
\hline
\end{tabular}

AST: Aspartate aminotransferase; ALT: alanine aminotransferase.

\section{Conclusion}

This study was terminated due to slow patient accrual; however, consolidation amrubicin following standard CCRT consisting of four cycles of etoposide-cisplatin plus concurrent TRT was feasible and demonstrated promising efficacy in patients with LS-SCLC.

\section{Conflicts of Interest}

The Authors declare no conflicts of interest in regard to this study.

\section{Authors' Contributions}

Y.H.K. designed the study. H.Y. and Y.H.K. contributed to the analysis and interpretation of data, and the writing of the article. 
H.N., Y.S., H.O., T.N., K.T., T.H., Y.M., Y.I., T.M., and K.Y. contributed to data collection and interpretation. All Authors reviewed the article.

\section{Acknowledgements}

No specific grant from funding agencies in the public, commercial, or not-for-profit sectors was received for this research.

\section{References}

1 Govindan R, Page N, Morgensztern D, Read W, Tierney R, Vlahiotis A, Spitznagel EL and Piccirillo J: Changing epidemiology of small-cell lung cancer in the United States over the last 30 years: Analysis of the surveillance, epidemiologic, and end results database. J Clin Oncol 24: 4539-4544, 2006. PMID: 17008692. DOI: 10.1200/JCO.2005.04.4859

2 Pignon JP, Arriagada R, Ihde DC, Johnson DH, Perry MC, Souhami RL, Brodin O, Joss RA, Kies MS, Lebeau B, Onoshi $\mathrm{T}$, Østerlind $\mathrm{K}$, Tattersall $\mathrm{M}$ and Wagner H: A meta-analysis of thoracic radiotherapy for small-cell lung cancer. N Engl J Med 327: 1618-1624, 1992. PMID: 1331787. DOI: 10.1056/ NEJM199212033272302

3 Turrisi AT 3rd, Kim K, Blum R, Sause WT, Livingston RB, Komaki R, Wagner H, Aisner S and Johnson DH: Twice-daily compared with once-daily thoracic radiotherapy in limited smallcell lung cancer treated concurrently with cisplatin and etoposide. N Engl J Med 340: 265-271, 1999. PMID: 9920950. DOI: 10.1056/NEJM199901283400403

4 Takada M, Fukuoka M, Kawahara M, Sugiura T, Yokoyama A, Yokota S, Nishiwaki Y, Watanabe K, Noda K, Tamura T, Fukuda $\mathrm{H}$ and Saijo N: Phase III study of concurrent versus sequential thoracic radiotherapy in combination with cisplatin and etoposide for limited-stage small-cell lung cancer: Results of the Japan Clinical Oncology Group Study 9104. J Clin Oncol 20: 3054-3060, 2002. PMID: 12118018. DOI: 10.1200/JCO. 2002.12.071

5 Hanada M, Mizuno S, Fukushima A, Saito Y, Noguchi T and Yamaoka T: A new antitumor agent amrubicin induces cell growth inhibition by stabilizing topoisomerase II-DNA complex. Jpn J Cancer Res 89: 1229-1238, 1998. PMID: 9914793. DOI: 10.1111/j.1349-7006.1998.tb00519.x

6 von Pawel J, Jotte R, Spigel DR, O'Brien ME, Socinski MA, Mezger J, Steins M, Bosquée L, Bubis J, Nackaerts K, Trigo JM, Clingan P, Schütte W, Lorigan P, Reck M, Domine M, Shepherd FA, Li S and Renschler MF: Randomized phase III trial of amrubicin versus topotecan as second-line treatment for patients with small-cell lung cancer. J Clin Oncol 32: 4012-4019, 2014. PMID: 25385727. DOI: 10.1200/JCO.2013.54.5392

7 National Cancer Institute, Cancer Therapy Evaluation Program: Common Terminology Criteria for Adverse Events (CTCAE), v4.0, published May 28, 2009. Available at: https://evs.nci.nih. gov/ftp 1/CTCAE/CTCAE_4.03/CTCAE_4.03_2010-0614_QuickReference_8.5x11.pdf
8 Eisenhauer EA, Therasse P, Bogaerts J, Schwartz LH, Sargent D, Ford R, Dancey J, Arbuck S, Gwyther S, Mooney M, Rubinstein L, Shankar L, Dodd L, Kaplan R, Lacombe D and Verweij J: New response evaluation criteria in solid tumours: Revised RECIST guideline (version 1.1). Eur J Cancer 45: 228247, 2009. PMID: 19097774. DOI: 10.1016/j.ejca.2008.10.026

9 Faivre-Finn C, Snee M, Ashcroft L, Appel W, Barlesi F, Bhatnagar A, Bezjak A, Cardenal F, Fournel P, Harden S, Le Pechoux C, McMenemin R, Mohammed N, O'Brien M, Pantarotto J, Surmont V, Van Meerbeeck JP, Woll PJ, Lorigan P and Blackhall F: Concurrent once-daily versus twice-daily chemoradiotherapy in patients with limited-stage small-cell lung cancer (CONVERT): An open-label, phase 3, randomised, superiority trial. Lancet Oncol 18: 1116-1125, 2017. PMID: 28642008. DOI: 10.1016/ S1470-2045(17)30318-2

10 Noda K, Nishiwaki Y, Kawahara M, Negoro S, Sugiura T, Yokoyama A, Fukuoka M, Mori K, Watanabe K, Tamura T, Yamamoto $\mathrm{S}$ and Saijo N: Irinotecan plus cisplatin compared with etoposide plus cisplatin for extensive small-cell lung cancer. N Engl J Med 346: 85-91, 2002. PMID: 11784874. DOI: 10.1056/NEJMoa003034

11 Kubota K, Hida T, Ishikura S, Mizusawa J, Nishio M, Kawahara M, Yokoyama A, Imamura F, Takeda K, Negoro S, Harada M, Okamoto H, Yamamoto N, Shinkai T, Sakai H, Matsui K, Nakagawa K, Shibata T, Saijo N and Tamura T: Etoposide and cisplatin versus irinotecan and cisplatin in patients with limitedstage small-cell lung cancer treated with etoposide and cisplatin plus concurrent accelerated hyperfractionated thoracic radiotherapy (JCOG0202): A randomised phase 3 study. Lancet Oncol 15: 106113, 2014. PMID: 24309370. DOI: 10.1016/S1470-2045 (13)70511-4

12 Sekine I, Sumi M, Satouchi M, Tsujino K, Nishio M, Kozuka T, Niho S, Nihei K, Yamamoto $N$, Harada $H$, Ishikura $S$ and Tamura T: Feasibility study of chemoradiotherapy followed by amrubicin and cisplatin for limited-disease small cell lung cancer. Cancer Sci 107: 315-319, 2016. PMID: 26748638. DOI: $10.1111 /$ cas. 12875

13 Horn L, Mansfield AS, Szczęsna A, Havel L, Krzakowski M, Hochmair MJ, Huemer F, Losonczy G, Johnson ML, Nishio M, Reck M, Mok T, Lam S, Shames DS, Liu J, Ding B, LopezChavez A, Kabbinavar F, Lin W, Sandler A and Liu SV: Firstline atezolizumab plus chemotherapy in extensive-stage smallcell lung cancer. N Engl J Med 379: 2220-2229, 2018. PMID: 30280641. DOI: 10.1056/NEJMoa1809064 